\title{
Improving Organization Performance: Project Management Approach Sustainable Development in Face of Globalization
}

\section{Itegi FM*}

Department of Education Management, Policy Studies, Kenyatta University, P.O. Box 43844-00100, Nairobi, Kenya

\begin{abstract}
Management ties together resources in an organization, mobilizes resources, and harmonizes efforts of all stakeholders to achieve organizational goals. Management in modern organizations have been challenged to adopt approaches that will keep organizations afloat. Arguably traditional approaches mainly aiming at effectiveness can no longer be relied on. This paper discusses project management approach in comparison to general management, its influence on organizational performance, highlight success cases and use of monitoring. It concludes that project management approach is core for organizational success and provides a flexible way to enhance continuous quality improvement, effective and efficient production within budget and set timelines.
\end{abstract}

Keywords: Effectiveness; Efficiency; Management; Organization; Project; Strategic and sustainability

\section{Introduction}

In the $21^{\text {st }}$ century contemporary approaches to management have continued to evolve influencing management thoughts. Stemming from the traditional theories pioneered by Fredrick Taylor, Henry Gantt and Lillian Gilbreth, the bureaucratic principles by Max Weber followed that focused on management as a profession that could be taught. These principles were supported by the likes of Henry Fayol, Chester Bernerd and Mary Perker Follet. Researchers Elton Mayo and Fritz established the importance of psychological and social processes on organization performance [1].

Among the contemporary approaches human capital theory gained prominence in demonstrating the focal point knowledgeable and trained human resource occupies in production; quantitative approach underscored the use of mathematical models and computer analysis; organizational behavior and the onset of systems approach so organizations operate as open systems depending on inputs from the external environment and transform them to outputs that meet market needs for goods and services. The management is expected to be on top of things to drive and even alter their customers taste by continuous improvement thereby surprising them with new services or products.

Modern organizations' management borrows heavily from Henry Gantt and Henry Fayol as proponents of planning and control to direct organizational change to match the social economic dynamics. In pursuant of millennium development goals, management thought shifted to strategic management with the realization that planning is core to organizational performance and growth.

Management is the process of implementing organizational objectives and planning for utilization of resources so as to achieve predetermined organizational goals. Traditionally effective and efficient management was viewed as that which promotes order and stability using rules and procedures. To achieve this management provided a structure in which activities are identified resources allocated, master routines are set, placements and procedures established to guide performance of duties. However, in this era of globalization sustainability overrides stability as organizations can no longer ignore the turbulence in external environment. Success of organizations today is determined by their ability to tap into the latest technology and adapting it to drive organizational processes to meet the ever changing demands of their stakeholders.
In traditional management approaches like strategic planning have not been followed up sufficiently to give expected results, thus project management approach comes as a solution where strategic projects are executed as per plan, budget and design generating results within set timelines. Organizations in the globally warmed business environment are faced with difficulties in maintaining greater market share amidst stiff competition from firms dealing with similar products. Customers today are looking for high quality products at cheaper prices even in produced in shorter durations. Continuous development and changes in the modern business world require planners to rethink the way they organize and manage their business for sustainability.

Governments and private firms have invested heavily in their enterprises and it is disturbing to note the high number of organizations that fail to meet their basic goals. In the developing countries most firms especially in public sector are "challenged" whereby they are not able to sustain their operations as they continue to draw resources from tax payers, while a significant percent have totally collapsed [2].

With the advancement of technology, sophistication of customers and increasing emphasis on globalization managers seem to be searching for new approaches to management enterprises. The project management approach does well in creating, acquiring and transferring knowledge and modifying behaviour to reflect new knowledge. While practitioners still assert that project management is a financial measure that cannot address complex issues associated with managing organizations, it emphasizes systematic problem solving, experimenting with new ideas, learning from experience of experts. This paper is to explore how project management approach can be adopted to make organizations gain a competitive advantage.

*Corresponding author: Itegi FM, Department of Education Management, Policy Studies, Kenyatta University, P.O. Box 43844-00100, Nairobi, Kenya, Tel: +2548703782; E-mail: muitegi.ku.ac@gmail.com

Recieved September 29, 2015; Accepted October 26, 2015; Published November 03, 2015

Citation: Itegi FM (2015) Improving Organization Performance: Project Management Approach Sustainable Development in Face of Globalization. J Entrepren Organiz Manag 4: 155. doi:10.4172/2169-026X.1000155

Copyright: (c) 2015 Itegi FM. This is an open-access article distributed under the terms of the Creative Commons Attribution License, which permits unrestricted use, distribution, and reproduction in any medium, provided the original author and source are credited. 


\section{Project management practice and organization sustainability}

The basic fundamentals of project management approach have been established as proper planning, design, execution and monitoring. The projects being selected help the organization to accomplish its intended strategy. What is required is a model that links decisions about selected projects to the organizational strategy. In many developing countries and especially in Kenya many governmental firms collapsed in the 1990s due to whole organization management approach. Such organizations continuously drew funds from the exchequer as departments and individual managers continued to perpetuate inefficiency and the outright lack of accountability. Many successful organizations today attest to the fact that managing multiple projects more strategically increases efficiency and effectiveness and improves organizational outcomes. Norrie [3] outlined key considerations in project management approach as: aligning projects to new organizational strategy; ability to measure strategic contribution of a single project for realization of benefits or as success criteria; the value of making investment in improved project practices; ability to tie project outcomes to strategic goals of the organization and stakeholder expectations; ensuring projects remain connected to organizations, emerging and changing business strategy and ability to draw joint conclusions dynamically and continually. More importantly project management approach allows for strategic trade-off decisions with choices such as delaying or cancelling existing projects in favour of newer initiatives that have higher strategic value for the same expenditure of resources. Projects help to express organizational strategy in measurable terms.

Project management involves application of knowledge, skills, tools and techniques in project environment to achieve the project objectives efficiently, effectively, and ethically. For the last decades governmental organisations, private organizations and individuals in many African countries have invested huge amounts of money in enterprises without proper procedures where such resources did not yield desired outcomes. Furthermore, in the public sector initiators are rarely held accountable for their failure, a culture that has continuously swindled these regions off their limited resources. Project management as a discipline evolved because of a need to coordinate activities to secure predictable results. In face of limited resources and the shift from processing raw materials to knowledge based economy in the world there is no organization or government that is willing to take chances in their investment. The focus is starting with the end in mind with the project team being held accountable for the utilization of resources for maximum benefits. Management therefore becomes a tool that is purchased as an important ingredient of enhancing project success.

The common project management tasks are establishing objectives, breaking work into well-defined tasks, charting the work sequence, scheduling, budgeting, coordinating the team, reporting and communicating feedback [4].

Project management is a modern approach that involves application and integration of project management process of initiating, planning, executing, monitoring and controlling to termination. Project management involves identifying requirements, establishing clear achievable objectives, balancing competing demands for quality, scope, time and cost, in addition to adopting the specifications, plans and approaches to different concerns and expectations of stake holders. Project management also respond to uncertainty which may have positive or negative effects on the organization and the management team is responsible to stakeholders including customers, the umbrella organization, the public and the members of project management institute PM1 so as to adhere to the project management professional
Ethics. Essentially high quality projects deliver the required products service or results within the scope, on time and within budget. Project management is sometimes used as a managerial approach in some organizations. Firms that wish to be competitive must select most appropriate projects, use techniques and procedures for portfolio selection based on most critical project measures [3].

In rapidly changing environment project management has become an essential survival requirement for most organizations today. As the project life cycle continue to decrease, new products and services must be developed and implemented as quickly and efficiently as possible. In addition products are becoming obsolete at an increasingly high rate. This requires that selection and development of new project be managed in a cost effective manner so that in face of limited resources there is production of unique high quality goods and services that maximizes the chances of commercial success.

Project management approach is a well-developed system that can enable organisations to meet their goals in a timely fashion. As a result project management has become an essential part of high technology management, a critical element in the globalization movement that has transformed world economy in the past ten years. By the end of 20 century virtually all type of industry around the globe begun to apply different aspects of project and portfolio management which is saw the dawn of sophistication and effectiveness that is today influencing the way companies do business, use resources and respond to market requirements with speed and accuracy [5]. However, the fast changing environments impose numerous times, financial, legal, ethical and logistic constraints forming a risky environment for business. Furthermore customers are now demanding new products at cheaper rates in shorter development time while the development process is becoming more complex. However, it's worth noting that most executives do not understand how to turn organizational strategy into projects that would improve the overall performance significantly. This situation has led to the growing numbers of project professionals at bachelor's degrees, masters and doctoral levels. In the period between 2004 and 2005, Lenovo Company sent its top talent to train for PMP certification to enhance project management standards where these professional were viewed as catalysts in the firm's processes as they trained team members in their departments.

A project is a complex set of activities where resources are used in expectation of returns and which leads it to planning, financing and implementing as a unit. A project usually has a specific starting point and ending point, intending to accomplish specific objectives. It's a well-defined sequence of investment and production activities and a specific group of benefits that can be identified, quantified and valued either socially or monetarily i.e. it's meant to improve the quality of life of people, they are units with a financial, economic and social impact [6]. At the country level development strategy require good projects with sound planning to attain desired goals as value for public resources.

\section{Importance of project management approach in organizational performance}

Projects contribute to the strategic direction of organizations and there are several reasons for embracing project management approach including: Achieving strategic goals shortening the product life cycle to ensure new products and services are released to the market as quickly as possible to achieve the organizational strategy and mission. In the light of this projects are screened to ensure those that do not support organizational objectives are terminated and their resources 
re-directed to more critical ones. In Lenovo's case study project management approach significantly advanced transformation of its' corporate strategy and improved business model.

To maintain organizations' competitive edge in globalized economy; organizations today are competing not only with others in their country or region but similar organizations worldwide. The global market today is driven by the demand for better cheaper, products and services e.g. ISO 9000: International standards for quality management and assurance which cover areas of design, procurement, and quality assurance and delivery controls entry into the world market. With increased pressures to reduce cost, more and more work is being classified as projects where individuals are assigned responsibility to achieve specific objectives within a given budget and by specified deadline. Project management approach is proving to be an efficient flexible way to have things done.

Improve organizational effectiveness: growth in knowledge has increased complexity of running business, including materials, product specifications, codes, aesthetics and equipment's and required specialists e.g. building a road 30 years ago was a simple process as compared to modern roads that need to determine present and potential customers' needs.

Need for corporate downsizing: With increased globalization organization cannot afford to pay for idle labour and missed priorities in allocation of scarce resources. Organizations are emphasizing on employing experts at higher pay than a mass of lowly paid labour that fails to deliver in constraints of time, cost and quality. They need flatter and leaner organizations where change is constant this is why project management approach is replacing middle level management. The lean production process aims at minimising waste while maximising quality of output. It emphasizes team work, where the teams take decisions and solve problems e.g. quality circles in Japan where top professionals would meet regularly to brainstorm on issues and challenges of economic development and suggest strategies to counter them. Many organizations are contracting individuals or groups to carry out specific tasks under specified conditions with the aim of cutting down spending on the workforce yet guaranteeing quality. Stevenson in his write up on competitive strategy and productivity argues that project management approach benefits from low cost outsourcing, use of capital intensive methods to achieve higher quality, Specialization by tapping expert knowledge to achieve higher quality, innovativeness to create new products and services, focus on response and customization and sustainability enhanced by environmental friendly and energy efficient operations. In East Africa project management approach is characterized by use of few experts on contract basis and a large number of casual workers who come in at different stages of the project and phase out as projects progresses to usher in others. This system helps organizations to cut on cost.

Reducing risks is a positive element associated with project management approach. It helps to identify potential risks and rectify them or initiate change management strategies to counter them. This helps the organization to save valuable resources by reducing the probability of being hit by unexpected event in a dynamic environment.

Increased customer focus is evident as customers in the modern world no longer simply settle for generic products and services. They want customized products and services that cater for their unique needs e.g. sale representatives work with their organizations to satisfy clients' requests. In firms where project management approach is being used projects to establish distribution channels. More importantly the variety of environmental forces interacting in today's business world contribute to the need for proper project management to enhance accountability, flexibility, innovation, speed and continuous improvement.

Pinto and Klastorin [7,8] outlined the following elements critical to the success of a project: clearly defined goals, competent project manager, top management support, competent project management team, sufficient resource allocation, adequate communication channels, control mechanism, feedback capabilities and responsiveness to clients. These elements must be embraced if modern enterprise is to succeed a dynamic environment.

\section{Project management approach success cases}

The project purpose is to create a product, service or a specified outcome. It is aimed at implementing a strategic programme, solve a problem of the sponsoring organization or individual entrepreneur or exploit an opportunity for commercial purposes

In some cases project are undertaken as "loss leaders" especially when an organization's main aim is to gain a competitive edge on a rival in a specific market. The recent projects in the mobile communication sector in East Africa have seen firms introduce products aimed at countering competition with the highest rivalry between Safaricom and Airtel earning the consumer the highest bargains ever. The competition has also engineered more investment in the firm's project management units to ensure new and unique products are released to the market frequently where products such as MPesa Vs Airtel Money and Mshwari and Equitel have dramatically changed the lives or people in the region in the world today.

Project oriented approach improves teamwork and creates a level playing field culture whereby an innovative culture is instilled. This culminates into improved organizations core competitiveness and delivery of services to customers. According to Lenovo's case study in 2006 the company had market share of 7\% in global PC market led by Dell and HP with a turnover of 14.6 billion US Dollar a 10\% rise from the previous year. This growth was associated with the establishment of project management office with many projects earmarked for strategic implementation and money set aside to execute projects outside the traditional budget.

In East and South Africa Kenyatta University increased the organization's market share from 15,000 students in 2005 to 75,000 students in 2014. This rise can be attributed to a shift from traditional management approaches to project management approach that saw the University engage in Public Private Partnerships increasing the resource base. Stemming from the institutional strategic plan 2005-2010 the University earmarked strategic projects including the Post Modern Library, Graduate School complex, School of Economics Building, KU teaching, research and referral hospital and the children's' hospital among others. The CEO with the University council passionately pursued this agenda ensuring projects followed set timelines and adhered to quality standards.

\section{Characteristics of successful projects}

In order to succeed using the project management approach, the following projects characteristics need to be borne in mind: Projects are temporary a project has a definite beginning and end e.g. when objectives have been achieved or it becomes clear that objectives cannot be met or the need for the project no longer exists and the project is terminated. Projects are not ongoing efforts but have a time frame. Once 
completed, they are terminated and handed over to the organization where they are integrated in relevant departments. Projects are unique they produces unique deliverables, products services or results e.g. many office building but each with a difference may be in terms of location, owner, interior design etc. Each project is an entity itself and requires different organizational structure and management styles. For example the division of labour depends on the technical aspects of the project and the type of products or services. Limited communication may be effective in a road construction as compared to developing software or developing a training program. Projects are constrained by scarce resources the Project Manager is usually presented with a document precisely listing a set of deliverables, a fixed budget and a firm schedule which they are expected to adhere to. Projects are planned financed and implemented and they involve attainment of specific measurable objectives. They are conducted in progressive elaboration with inbuilt monitoring in all steps.

The fact that projects are completed in a finite time and resources usually drawn from other parts of the organization makes them different from other activities. It is important to note that projects do not exist in isolation. They are often parts of a larger entity, organization or programs. For example the devolution program in Kenya has been accompanied by many flagship projects in various sectors of the economy such as the economic stimulus, Constituency development Fund, Youth Development Fund and Women Enterprise Fund to accelerate development in Devolved units. The infrastructural development program in Kenya is manifested in various projects such as Construction of by-passes in Nairobi area including the multibillion Nairobi-Thika supper high way project, Northern, Southern and Eastern by-passes as well. Projects are therefore subdivisions of programs which continue indefinitely and are larger in scope. However projects are composed of tasks which can be further subdivided into subtasks. Unlike program managers project managers strive to put themselves out of business as quickly as possible because projects have set timelines [8]. This makes project management approach more suitable especially where techniques and procedures for project portfolio selection is well understood by managerial decision makers.

An organization can succeed only by doing projects right and doing the right projects. It must have a project portfolio that is consistent with the overall goals and strategy while maintaining required diversification, adequate cash flows and not exceeding resource constraints. Projects are initiated to realize process, program, or organizational improvements in order to improve existing conditions or exploit new opportunities. Some projects result from critical factors or competitive necessity while others are meant to maintain or expand market share.

Organisations undertake different kinds of projects: compliance and emergency are projects needed to meet regulatory requirements to operate in a region and these usually have penalties if not implemented; Operational projects are designed to improve efficiency of organizational systems, and performance while strategic projects directly support the organization mission, help to increase revenue or market share by introducing new products or services for organizational development. Selection approaches engage questions touching on qualitative and quantitative factors. The bottom-line is what is the proposed projects' relationship with the organization's overall mission and strategy? Among the agendas giving African CEOs sleepless nights was organizational growth; growing customer base and enhancing service. They further observed the need to develop new products, anticipate and meet the changing needs of customers has been a critical challenge for managers [9].

\section{Project selection criteria}

Project selection is the process of evaluating a project or a group of projects and then choosing to implement it or a set of them so that the goals of the organization are achieved. This is a formal process through which a project is approved by a committee of senior managers to ensure several conditions are considered before a project is undertaken. The common ones as outlined by Mantel, Meredith, Shafer and Sutton [10] are: Is the project potentially profitable? Does it have a chance of meeting our return on investment? Does the firm have or can it easily acquire the skills to carry the project to success? Does the project involve building competencies that are consistent with the organization's strategic plan? Does the organization have the capacity to carry out the proposed project on proposed schedule? The methods for selecting are typically identified as financial or non-financial. These measures are helpful in evaluating the potential value or profitability or projects and are applied in initial stages of selection and planning sometimes even before a project manager is appointed.

\section{Project appraisal and selection for organizational efficiency and effectiveness}

Project selection is the process of evaluating individual projects or a group of projects and then choosing to implement one or a set of projects to achieve organizational goals. It's a formal process conducted by a committee of senior managers to make sure several conditions are met before a commitment is made to undertake any project. It may also involve a critical review of the proposed projects by an independent team of experts in consultation with stakeholders and to ensure the investment meets the needs of beneficiaries and investors in terms of priorities and is feasible given the resources available.

Project appraisal involves technical experts in the field projects examines whether it's practical; financial experts confirms proper provisions and proper budgeting; commercial appraisal on issues related to source of raw materials, market, the competitors and pricing; social cultural appraised assessing how the project affects the culture of the society; managerial and organizational appraisal focusing on the hierarchy of power and the match between tasks to the people responsible while environmental appraisal assesses the impact of the project on the environment including pollution or displacement of people [6].

Selection and appraisal helps to mitigate the negative effects and develop solutions to possible problems e.g. treating of waste. It helps to come up with sustainable development. After appraisal viable projects are selected for implementation. From the foregoing project management approach provides a balance between economic, social development while taking care of the environment.

The success of the project is pegged on having the right people in the right places with right skills, positive attitude to work and the management ability to co-ordinate the team effort. Monitoring of progress and reporting feedback becomes a crucial process of refinement as the tasks progress i.e. learning from experience and initiating corrective measures when need arises. The management becomes proactive by investigating activities as work continues with a view to finding out what is working and where plans need to be adjusted to give better results. Teams in organisations are encouraged to seek ways of improving their performance continuously and not settling at the already established levels of excellence. The management team 
and technical experts must ensure constant access to information from within and outside the project to ensure the project benefits from the latest technological advancement and address present and future needs of beneficiaries. This can only be achieved if the management ensure right people with right skills are in place, are provided with resources and information and are allowed to put their ideas to test [2].

Amateurs in project management usually get into the job as soon as the resources are supplied just to land into crisis for lack of proper planning and coordination. This happens when project teams are under pressure to complete project implementation and give accountability to donors. In such cases, time taken to clarify plans, establish roles and responsibilities of groups and individuals and putting in place monitoring and review system are often considered as a waste of time. In the view of Mulwa [4], a concise project plan is key to have the project move through investment phase (gathering resources), development phase (production builds up) to full development whereby production peaks up and continues to the project termination phase.

\section{Project monitoring for enhanced organizational products or services}

Project management approach introduces monitoring is an ongoing activity in the various stages carried out either by beneficiaries, implementing staff supervisory staff and project management staff. Its aim is to ensure activities are undertaken as scheduled and according to design. Monitoring is a routine process of collecting, analyzing and interpretation in order to make decisions while activities are going on so as to introduce necessary changes that are likely to benefit the project. By managing project data the monitoring team provides feedback as pertains to the progress of a project.

According to UNCRD [6] monitoring is the periodic review of inputs, activities and outputs during implementation. It involves review of procurement and delivery of inputs, schedule of activities, and progress in production of outputs. It is the process of collecting information about the actual performance during implementation and adopting control strategies to fill the gap between the actual and planned. Thus Project management approach can be adopted to minimize risks and maximize opportunities to meet the demands of various stakeholders.

Monitoring and evaluation attempts to determine as objectively as possible, the relevance, effectiveness and efficiency in the project work, the impact of activities in the light of specified objectives. It involves: directing, guiding, controlling work in progress; collecting necessary information and providing feedback; negotiating for materials, supplies and services; resolving differences during project implementation.

During monitoring constraints in operational design are detected and corrective measures taken. The team monitors deviations from the plan and determines whether they are caused by environment or structural problems and appropriate actions are taken to bring performance back to the track. This requires the management to be proactive rather than reactive. To succeed channels of communication should be clear and easy to ensure accountability for all staff to enhance smooth implementation [11-16].

The control process starts from information gathered from the monitoring process including: Timesheets showing effort booked to set dates on a task, effort still remaining to complete the task and predicted end date. Quality reviews indicate whether deliverables are meeting defined criteria (set standards) and financial data shows trends of costs of resources expended and those expected in future. The project manager considers whether the task is expected to get behind schedule, whether it is on the critical path, consider if available slack/ float time is sufficient to accommodate it. If on the critical path what will be the knock on effect where all available alternatives must be explored to ensure it is completed on time as much as possible. This rigor introduces the culture of accountability and professionalism in the organization with immense tradeoffs.

In terms of quality the pertinent issue is whether the defects discovered affects the ability to deliver a conformant product. Is there need for rework? Is it one off problem or one that has deeper roots such as lack of necessary skills? Imprecise specifications or too tight time scale?

In case of cost overruns the manager seeks to establish whether the project is likely to get over budget, can the costs be overcome by using cheaper alternatives? Or is there need to renegotiate the budget? In essence project management approach has proved to be an effective and efficient way of enhancing organizational performance especially in this era of globalization where continuous improvement is the market leader.

\section{Conclusion}

Leading Organizations in this modern time are those with leaders who have been able to disaggregate their organizations into series of project whose performance is monitored and evaluated before they are integrated into the system. Project portfolio management is the mainstay of successful leaders who cannot afford to drive whole organizations that are likely to go under. The approach help them to determine performance using planned budget or schedules which is quite easy if individual milestones have been reached as compared to measuring revenues or qualitative subjective factors. If project ideas are well natured, appraised and sufficient resources devoted for their successful implementation, project management approach is one of the most essential elements in executing an organizational strategy with increased efficiency and effectiveness.

\section{Refernces}

1. Bateman M (2012) The Evolution of Management. McGrawHill.

2. Itegi F (2014) Introduction to Project Management: Theory to practice. Nairobi: Catholic University Press.

3. Norrie J (2006) Improving Results of Project Portfolio Management in the Public Sector Using Balanced Scoring Model. Royal Melbourne Institute.

4. Mulwa FW (2008) Participatory Monitoring and Evaluation of Community Projects. Nairobi: Paulines.

5. Schwalbe K (2006) Introduction to Project Management. Augsburg: Thomson.

6. United Nations Centre for Regional Development (UNCRD) (2000) Project Planning, Implementation and Evaluation: A Training Manual. Nairobi.

7. Pinto JK (2007) Project Management: Achieving Competitive advantage. London: Pearson Prentice Hall.

8. Klastorin T (2009) Project Management: Tools and Tradeoffs. Washington: John Willey and Sons Inc.

9. Kenya Institute of Management (2014) Management: Success, Influence and Inspiration.

10. Mantel S, Jack M, Shafer M, Sutton M (2008) Project Management in Practice. Manhattan: Willey.

11. Candle J, Yeats D (2008) Project Management for Information Systems: (5thedn), Amazon: Prentice Hall.

12. Klastorin T (2004) Project Management. Washington: John Willey and Sons Inc 
Citation: Itegi FM (2015) Improving Organization Performance: Project Management Approach Sustainable Development in Face of Globalization. J Entrepren Organiz Manag 4: 155. doi:10.4172/2169-026X.1000155

Page 6 of 6

13. Lewis J (2007) Fundamentals of Project Management. New York: Amacom.

14. Chadra P (1995) Projects, Planning, Analysis, Selection, Financing, Implementation and Review. New Delhi.
15. Standish Group (1999).

16. Stevenson (2015) Competitive Strategy and Productivity at Stevenson. 